BMJ Paediatrics Open

\title{
Inequalities in child health in India
}

\author{
Binu Pappachan, ${ }^{1}$ Imti Choonara ${ }^{2}$
}

To cite: Pappachan B, Choonara I. Inequalities in child health in India. BMJ Paediatrics Open 2017;1:e000054. doi:10.1136/ bmjpo-2017-000054

- Prepublication history for this paper is available online. To view these files please visit the journal online (http://dx.doi.org/ 10.1136/bmjpo-2017-000054).

Received 27 April 2017 Revised 14 June 2017 Accepted 17 June 2017

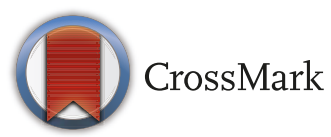

${ }^{1}$ Dept of Paediatrics, Lourdes Hospital, Kochi, Kerala, India ${ }^{2}$ Academic Unit of Child Health, University of Nottingham, Derbyshire Children's Hospital, Derby, UK

Correspondence to Prof. Imti Choonara; Imti. Choonara@nottingham.ac.uk

\section{ABSTRACT}

India is a lower-middle-income country with one of the fastest growing economies in the world. Despite improvements in its economy, it has a high child mortality rate, with significant differences in child mortality both between and within different states. Poverty, malnutrition and poor sanitation are major problems for many Indians and are a major contributor to child mortality. More than $40 \%$ children are malnourished or stunted. Healthcare provision is poor, and many families, especially in rural areas, have major difficulties in accessing healthcare. Kerala has the lowest child mortality rates in India. This has been achieved by reducing poverty, malnutrition and inequalities. The provision of universal education alongside universal access to healthcare has demonstrated that child mortality rates could be reduced. India could significantly reduce its child mortality by following the example of Kerala.

\section{INTRODUCTION}

India is a lower-middle-income country with the second largest population in the world. It is one of the G20 major economies worldwide, and over the last two decades has had an average growth rate of approximately $7 \%$. In 2014, it became the world's fastest growing major economy. ${ }^{1}$ Despite this economic success, it has a high child mortality rate, and one in five deaths in children under the age of 5 years worldwide occurs in India. ${ }^{2}$ Child mortality rates in India are higher than in neighbouring Bangladesh and Nepal, both of which are poorer and have fewer doctors (table 1$).^{3-5}$ India failed to achieve its millennium development goal targets for child mortality. ${ }^{5}$ India consists of 35 separate states, each of which has its own government. ${ }^{6}$ There are major differences between the states economically and politically. ${ }^{6}$ This review aims to highlight some of the problems relating to child health in India and describe some of the reasons.

\section{Poverty and malnutrition}

Socioeconomic determinants play a major role in the health of young children. ${ }^{78}$ Improving sanitation has been shown to have a significant effect on reducing child mortality. ${ }^{9}$ Only $36 \%$ of the population in India have access to improved sanitation facilities. ${ }^{3}$ Poverty and malnutrition are major problems in India.
Over $40 \%$ of children are underweight, ${ }^{10}$ and more than one in four babies have low birth weight. ${ }^{10}$ In rural areas, over $45 \%$ of children under the age of 5 are underweight. One in three of the population lives below the international poverty line of US $\$ 1.25$ per day. ${ }^{10}$ Poverty and malnutrition are closely linked, and approximately $45 \%$ of all deaths of children under the age of 5 years are linked to malnutrition. ${ }^{11}$ Inequalities are a major problem throughout most of India. Even in the richest state in India (Maharashtra), more than one in three children are underweight. ${ }^{11}$ The reduction of poverty and malnutrition would have a major impact on child mortality throughout India. This is illustrated by the example of Kerala, which has successfully reduced poverty and malnutrition, and has the lowest child mortality rates in India (table 2). The actions of the government in Kerala to reduce inequalities have been a deliberate political decision. ${ }^{12}$

\section{Healthcare provision}

The government provides public healthcare, but only $1.1 \%$ of gross domestic product (GDP) is allocated to health. In contrast, 2.7\% of GDP is allocated to military spending. ${ }^{10}$ The private medical sector is the primary source of healthcare for the majority of the population in both urban and rural areas. ${ }^{13}$ Approximately, two-thirds of the population seek healthcare from the private medical sector. Even in rural areas, $63 \%$ of the population go to a private provider. There are numerous private healthcare providers, and this results in a lack of coordination in healthcare facilities. The private medical sector in India is extensive and politically influential, with little desire to see implementation of universal healthcare. ${ }^{14}$ The need for universal healthcare in India is well recognised by health professionals. $^{15} 16$ The majority of Indians cannot afford private healthcare. Only $5 \%$ of households have any health insurance. ${ }^{13}$

The National Family Health Survey (NFHS-3) interviewed family members to identify why individuals did not use government health facilities. ${ }^{13}$ The two main reasons were the poor quality of care and the lack of 


\begin{tabular}{llll} 
Table 1 & Child mortality in India, Bangladesh and Nepal \\
\hline Country & $\begin{array}{l}\text { U5 mortality } \\
\text { rates }^{*}\end{array}$ & $\begin{array}{l}\text { GNP per } \\
\text { capita† }\end{array}$ & $\begin{array}{l}\text { Physicians per } \\
\mathbf{1 0 0 0 0} \text { population }\end{array}$ \\
\hline India & 52.7 & 5350 & 7.0 \\
Bangladesh & 41.1 & 2810 & 3.6 \\
Nepal & 39.7 & 2260 & 2.0 \\
\hline
\end{tabular}

Data from WHO 2015. ${ }^{34}$

*Under 5 mortality rates are expressed per 1000 live births. †Purchasing power parity at international dollar rate. GNP, gross national product.

a government health facility in the area. Other reasons were that the waiting time was too long in government health facilities and health personnel were often absent from the government health facilities. A major problem for rural women was the distance to a health facility. Concerns were also expressed that there may not be any drugs available at the health facility. ${ }^{13}$

Recent welcome developments in healthcare provision include the programme for Accredited Social Health Activists (ASHA). These individuals can visit newborns and families at home and give advice regarding nutrition, infections and feeding. The benefit of ASHAs has been shown by a cluster randomised control trial that showed a significant decrease in the neonatal mortality rate in areas where ASHAs supported women's groups. ${ }^{17}$

Another welcome initiative was the establishment in 2005 of the National Rural Health Mission. ${ }^{18}$ This is a public scheme that recognised that many poor households in remote rural areas did not have adequate access to healthcare. Other positive developments have been the provision of cash transfers to pregnant women and the expansion of inpatient coverage for the poor. ${ }^{18}{ }^{19}$ Several other initiatives have been introduced by different states - all with the aim of expanding access to healthcare. ${ }^{20}$ Despite these initiatives, India fails to provide universal healthcare for many of its children.

\section{Maternal health}

The health of the mother is clearly related to the health of the child. A malnourished mother is likely to result in malnutrition in the young infant. Antenatal care is crucial for the birth of a healthy baby. One in five women in India receives no antenatal care. ${ }^{13}$ There are huge variations in the provision of antenatal care across India (table 2). Antenatal care is almost universal in Kerala, Tamil Nadu and Goa. The NFHS-3 looked at nine summary indicators of the utilisation of antenatal care services. Kerala, Tamil Nadu and Goa ranked in the top five states in the country in almost all of the indicators. ${ }^{13}$ Bihar, Rajasthan, Uttar Pradesh and Jharkhand are large states that all perform poorly in the provision of antenatal care. The problems in accessing healthcare are illustrated by a study from southern Odisha, ${ }^{21}$ which highlighted the practical problems by pregnant women accessing healthcare. The main problem was physically getting to the hospital. Almost half the women had to hire an auto rickshaw in order to get to the hospital. The difficulties experienced by women in accessing healthcare has been raised as a human rights issue. $^{22}$

Only one-third of babies born in the 5 years preceding the NFHS-3 survey had their birth weight recorded. The percentage of babies with a recorded birth weight ranged from $97 \%$ in Kerala to $8 \%$ in Uttar Pradesh. ${ }^{13}$ The lack of antenatal care for many women during the pregnancy is probably one of the major reasons for the high maternal mortality ratio in India. Kerala and Tamil Nadu, which both have excellent antenatal care, have achieved the millennium development goal target of a maternal mortality ratio of 109 deaths per 100000 live births. ${ }^{23}$ The states with the poorest antenatal care also had the highest maternal mortality rate ratios. ${ }^{23}$

\section{Empowerment of women}

Women play a crucial role in the health of children. Empowerment of women is crucial for the health of children. ${ }^{1224}$ One in three women is illiterate. In many rural areas, women need to seek permission from a man in the family before being allowed to travel or use money to pay for either healthcare consultations or drug treatment. ${ }^{13} 21$ Even within urban areas, the financial autonomy of women is a key determinant of child health. ${ }^{25}$ The NFHS-3 asked numerous questions about the empowerment of women in India. They found a direct relationship between the empowerment of women and lower child mortality rates (neonatal, infant and under 5 mortality rates). It is no coincidence that Kerala, which has the best education of women, also has the best health outcomes for

Table 2 Regional variations in healthcare

\begin{tabular}{lllll}
\hline State & $\begin{array}{l}\text { Women who received no } \\
\text { antenatal care (\%) }\end{array}$ & Perinatal mortality rate $^{*}$ & Infant $_{\text {mortality rate }}^{*}$ & U5 $_{\text {mortality rate }}$ \\
\hline Kerala & 0.1 & 10.8 & 15.3 & 16.3 \\
Maharashtra & 7.3 & 35.8 & 37.5 & 46.7 \\
Bihar & 65.7 & 58.7 & 61.7 & 84.8 \\
Uttar Pradesh & 33.5 & 59.5 & 72.7 & 96.4 \\
India & 22.8 & 48.5 & 57.0 & 74.3 \\
\hline
\end{tabular}

Data from 2005 to 2006, National Family Health Survey-3. ${ }^{11}$

*Mortality rates are all expressed in relation to the number of deaths per 1000 live births. 
children. Education alongside financial autonomy are key determinants of child health in India. ${ }^{25}$

\section{Breast feeding}

Breast feeding is almost universal in India. However, very few children are put to the breast immediately after the birth. Only a quarter of infants started breast feeding within an hour of birth and only 55\% started breast feeding within the first 24 hours. ${ }^{13}$ The majority of mothers $(57 \%)$ in the first 3 days after delivery gave their infants other liquids (other milks, honey, water or glucose water). The value of education for the mothers is illustrated again by Kerala, where $95.7 \%$ of mothers started breast feeding within 1 day of birth; in contrast only 23\% of mothers in Uttar Pradesh started breast feeding within the first 24 hours. Infant mortality is greatest in the neonatal period, and the 48 hours immediately following birth is the most crucial period. The reluctance to initiate breast feeding in the first 24 hours will increase neonatal mortality rates. Again, Kerala with its high breast feeding in the first 24 hours and universal provision of antenatal care has the lowest perinatal mortality rate (table 2 ).

\section{Immunisation}

Immunisation plays a crucial role in reducing infant and child mortality. The WHO considers infants fully vaccinated if they have received Bacillus CalmetteGuérin (BCG) against tuberculosis, three doses of the diphtheria pertussis and tetanus vaccine, three doses of the polio vaccine and one dose of the measles vaccine by the age of 12 months. ${ }^{13}$ Unfortunately, only $36 \%$ of children were fully vaccinated by the age of 12 months. The highest percentage rate of all immunisations was in Tamil Nadu (80.9\%). Kerala and Goa both had immunisation rates above $75 \%$. In contrast, Uttar Pradesh only achieved immunisation rates of $23 \%$ and Nagaland achieved immunisation rates of $21 \%$.

\section{Access to healthcare: antibiotics for respiratory tract} infection (RTI), oral replacement solution for diarrhoea

Acute respiratory tract infections are one of the leading causes of the death of children throughout the world. Early diagnosis with treatment with antibiotics can save many lives. In the NFHS-3, $6 \%$ of children showed symptoms of an acute respiratory tract infection in the 2 weeks preceding the survey. In $69 \%$ of the cases, treatment was sought from a health facility or provider. ${ }^{13}$ This percentage ranged from $60 \%$ in the lowest quintile in relation to wealth, to $80 \%$ in the highest quintile. When comparing different states, there were marked differences in the percentage of children for whom treatment was sought from a health facility. The lowest percentage was in Nagaland, where only $27 \%$ sought treatment. In contrast, in both Delhi and Kerala, $89 \%$ sought treatment. Not every child with an acute respiratory tract infection requires antibiotics. Overall, $12 \%$ of all children received antibiotics. This ranged from $6 \%$ in the lowest quintile for wealth to $20 \%$ in the second highest quintile for wealth. Only $1 \%$ of the children in the state of Chhattisgarh with symptoms of an acute respiratory tract infection received antibiotics. This contrasted with $46 \%$ in Uttaranchal.

Diarrhoea is the second most common cause of death in children under the age of 5 . In the vast majority of cases, simple rehydration can prevent death. In the NFHS-3 survey, $9 \%$ of children had diarrhoea in the 2 weeks preceding survey. ${ }^{13}$ Overall, $60 \%$ of children with diarrhoea were taken to a health provider. Again, there were significant differences in the percentage of children taken to a health provider in relation to income, ranging from $50 \%$ in the lowest quintile and $73 \%$ in the highest quintile. Overall, $43 \%$ of children received oral rehydration therapy or increased fluids. Only $37 \%$ of children in the two lowest quintiles in relation to wealth received either oral rehydration therapy or increased fluids. This contrasted with $59 \%$ of children in the highest quintile for wealth. There were marked regional variations in the provision of treatment with oral rehydration therapy or increased fluids. Eighty-five per cent of children in Kerala received oral replacement therapy (ORT) or increased fluids. In contrast, only 25\% of children in Assam and Rajasthan received ORT or increased fluids.

\section{Anaemia}

Anaemia is a major problem in children throughout India. Almost $70 \%$ of children under the age of 5 years in India are anaemic. ${ }^{13}$ There are only four states in India in which less than half of the children are anaemic (Goa, Kerala, Manipur and Mizoram). In five states, more than $70 \%$ of children are anaemic.

Anaemia is also a significant problem for adults throughout India. Approximately, one in four men is anaemic and $55 \%$ of women are anaemic. ${ }^{13}$ Again, there are major regional variations in the prevalence of anaemia in women in India. The four states (Goa, Kerala, Manipur and Mizoram) with the lowest prevalence of anaemia in children also had the lowest prevalence of anaemia in women $(33 \%-38 \%)$.

\section{LEARNING FROM KERALA}

Kerala is not the richest state in India. It is however the state that over the last 20-30 years has reduced poverty the most. It has also invested in public health and education. This has been due to a combination of several factors. Progressive governments, civil society engagement and an educated population have all contributed to a deliberate attempt to reduce inequalities. ${ }^{12} 2627$ Empowering women through collective action has been particularly successful. ${ }^{12}$ Kerala has the best figures throughout India for access to healthcare, and in particular in relation to the provision of antenatal care for pregnant women. It has a high immunisation uptake rate, and these have played a major role in ensuring that it has the lowest under 5 mortality rate in India (box 1). It is disappointing, but not surprising, that the Indian government, 


\section{Box 1 How Kerala has improved child health}

- Reduce poverty

- Reduce malnutrition

- Reduce inequalities

- Ensure universal education

- Ensure universal access to healthcare

- Ensure all pregnant women receive antenatal care

Provide universal immunisation

which has accepted neoliberalism, has failed to replicate the measures taken by Kerala as these would have a significant impact on reducing the excessive child mortality in India.

Contributors Both authors have contributed to the review and have agreed the final version.

Competing interests None declared.

Patient consent None.

Provenance and peer review Commissioned; externally peer reviewed.

Data sharing statement None.

Open Access This is an Open Access article distributed in accordance with the Creative Commons Attribution Non Commercial (CC BY-NC 4.0) license, which permits others to distribute, remix, adapt, build upon this work non-commercially, and license their derivative works on different terms, provided the original work is properly cited and the use is non-commercial. See: http://creativecommons.org/ licenses/by-nc/4.0/

(c) Article author(s) (or their employer(s) unless otherwise stated in the text of the article) 2017. All rights reserved. No commercial use is permitted unless otherwise expressly granted.

\section{REFERENCES}

1. OECD. Economic survey of India, 2017.

2. Khurmi M, Gupta M, Patle A, et al. Improving child survival under National Health Mission in India: where do we stand? Indian J Child Health 2015;2:49-54.

3. World Health Organisation. World Health Statistics, 2015.

4. Shankar PR. Attracting and retaining doctors in Rural Nepal. Rural Remote Health 2010;10:1420.

5. UNICEF. Levels \& trends in Child Mortality, 2015.

6. Cowling K, Dandona R, Dandona L. Social determinants of health in India: progress and inequities across states. Int $J$ Equity Health 2014:13:88.
7. Spencer $\mathrm{N}$. The effect of income inequality and macro-level social policy on infant mortality and low birthweight in developed countries--a preliminary systematic review. Child Care Health Dev 2004;30:699-709.

8. Smith LK, Manktelow BN, Draper ES, et al. Nature of socioeconomic inequalities in neonatal mortality: population based study. BMJ 2010;341:c6654.

9. Gouda J, Gupta AK, Yadav AK. Association of child health and household amenities in high focus states in India: a district-level analysis. BMJ Open 2015;5:e007589.

10 . Statistics UNICEF. India. www.unicef.org. Accessed on 21stJanuary 2016.

11 . WHO. www.who.int/mediacentre/factsheets/fs178/en/. Accessed on 21stJanuary 2016.

12. Panackal N, Singh A, Hamsa S. Kudumbashree and women empowerment in Kerala - an overview and theoretical framework. Indian Journal of Commerce \& Management Studies 2017.

13. National Family Health Survery (NFHS-3) 2005-06, India volume 1.

14. Sengupta A, Prasad V. Towards a truly universal indian health system. Lancet 2011;377:702-3.

15. Balarajan $Y$, Selvaraj S, Subramanian SV. Health care and equity in India. Lancet 2011;377:505-15.

16. Reddy KS, Patel V, Jha P, et al. Towards achievement of universal health care in India by 2020: a call to action. Lancet 2011;377:760-8.

17. Tripathy P, Nair N, Sinha R, et al. Effect of participatory women's groups facilitated by Accredited Social Health Activists on birth outcomes in rural eastern India: a cluster-randomised controlled trial. Lancet Glob Health 2016;4:e119-e128.

18. Akseer N, Kamali M, Arifeen SE, et al. Progress in maternal and child health: how has South Asia fared? BMJ 2017;357:j1608.

19. Lim SS, Dandona L, Hoisington JA, et al. India's Janani Suraksha Yojana, a conditional cash transfer programme to increase births in health facilities: an impact evaluation. Lancet 2010;375:2009-23.

20. Zaidi S, Saligram P, Ahmed S, et al. Expanding access to healthcare in South Asia. BMJ 2017;357:j1645.

21. Mahapatro M. Equity in utilization of health care services: perspective of pregnant women in southern Odisha, India. Indian J Med Res 2015;142:183-9.

22. Ram F, Singh A, Ram U. Human rights approach to maternal \& child health: has India fared well? Indian J Med Res 2013;137:721-7.

23. Maternal \& Child Mortality and Total Fertility Rates - Sample Registration System (SRS).. Office of Registrar General, India. 7th July 2011.

24. Shroff MR, Griffiths PL, Suchindran C, et al. Does maternal autonomy influence feeding practices and infant growth in rural India? Soc Sci Med 2011;73:447-55.

25. Agarwal S, Srivastava A. Social determinants of children's health in urban areas in India. $J$ Health Care Poor Underserved 2009;20:68-89.

26. Narayan R. Universal health care in India: missing core determinants. Lancet 2011:377:883-5.

27. Kannan KP. Poverty alleviation as advancing basic human capabilities: kerala's achievements compared. 1999: CDS working papers, no.294. Trivandrum. http://opendocs.ids.ac.uk/opendocs/ handle/123456789/3007. 